\title{
Arthroscopic Treatment of Femoroacetabular Impingement of the Hip
}

\author{
A New Technique to Access the Joint
}

\author{
Monika Horisberger MD, Alexander Brunner MD, \\ Richard F. Herzog MD
}

Received: 9 November 2008/Accepted: 13 July 2009/Published online: 30 July 2009

(C) The Association of Bone and Joint Surgeons (B) 2009

\begin{abstract}
Femoroacetabular impingement has been established as an important cause of groin pain and limitation of range of motion in young, active patients and a possible cause for early osteoarthritis of the hip. Open surgery is a well-recognized approach for treatment and probably the standard for most surgeons, but recent reports regarding arthroscopic treatment procedures suggest comparable results. We present a technique that provides a way to securely penetrate the joint capsule and evaluate the clinical results of this technique in patients with femoroacetabular impingement. Between 2004 and 2007, we prospectively followed a cohort of 105 hips ( 88 patients; 60 males, 28 females) who underwent surgery for symptomatic cam or mixed femoroacetabular impingement. All patients were evaluated for the Nonarthritic Hip Score, clinical parameters, visual analog scale pain score, initial radiographic degenerative changes, and alpha angle. At a minimum followup of 1.3 years (average, 2.3 years; range, 1.3-4.1 years), all clinical outcome measures improved. The Nonarthritic Hip Score improved from 56.7 points (range, 15-92.5 points) to 84.6 points (range, 47.5-100 points). Nine patients (8.6\%) underwent THA during followup. The outcome measures after
\end{abstract}

Each author certifies that he or she has no commercial associations (eg, consultancies, stock ownership, equity interest, patent/licensing arrangements, etc) that might pose a conflict of interest in connection with the submitted article.

Each author certifies that his or her institution has approved the human protocol for this investigation, that all investigations were conducted in conformity with ethical principles of research, and that informed consent for participation in the study was obtained.

M. Horisberger ( $₫)$, A. Brunner, R. F. Herzog

Orthopaedic Department, Cantonal Hospital Lucerne, 6110

Wolhusen, Switzerland

e-mail: Monika.Horisberger@hotmail.com arthroscopic therapy for femoroacetabular impingement seem comparable to those reported after open procedures.

Level of Evidence: Level IV, therapeutic study. See Guidelines for Authors for a complete description of levels of evidence.

\section{Introduction}

Femoroacetabular impingement (FAI) has been recognized as a cause of hip pain, decreased range of motion (ROM), and labral and chondral abnormalities [3, 18, 32]. Repetitive microtrauma at flexion and internal rotation can cause chronic pain resulting from abutment of the femoral headneck junction and the acetabular rim. This is caused by an abnormal peripheral increasing radius of the femoral head (cam impingement) or acetabular overcoverage (pincer impingement). Chronic impingement can lead to degenerative labral tears and acetabular chondral degeneration, which, in turn, may contribute to the development of early osteoarthritis $[4,13,18,36]$. Surgical treatment of hip impingement caused by an abnormal head-neck offset, whether alone or in combination with overcoverage of the acetabulum (mixed impingement), improves symptoms, restores morphologic features of the hip, and ultimately may delay the progression of degenerative joint disease.

Currently surgical dislocation and open correction for impingement as originally proposed by Ganz et al. [12] is the most widely accepted surgical approach for treating FAI. Numerous authors have reported substantial postoperative increases in different outcome measures [4, 15, 25, 28]. However, it is associated with large surgical exposure and partial weightbearing for several weeks [12]. As much as $24 \%$ of patients reportedly undergo screw removal from the greater trochanter because of persistent bursitis and pain [1]. 
To avoid these problems associated with open surgery, arthroscopic offset correction is an up-and-coming procedure and usually can be performed on an outpatient basis. The accuracy and precision of this procedure have been confirmed [34, 35]. One study reported on 19 patients with a substantial increase in WOMAC score after 2 years [17]. Another investigation on 100 arthroscopic operations for FAI reported an increase of the modified Harris hip score from 60.8 to 82.7 points at 1-year followup [21]. Reported complications with arthroscopic treatment are minor in nature and include temporal paresthesias and cutaneous lesions in the genital area resulting from positioning of the traction device [6].

Because arthroscopic correction for FAI is a new procedure and experience is limited, several surgical methods have been described [19]. Difficulties with this procedure include safe entering of the joint capsule and problems with limited observation resulting from small and inflexible capsule-entering points or in cases with a thickened joint capsule $[20,38]$.

We describe a technique providing a way to securely penetrate the joint capsule, enabling sufficient observation of the pathologic head-neck region and arthroscopic correction for FAI. We then report (1) the complication rate; (2) the number of patients who had subsequent THA; and (3) the Nonarthritis Hip Score (NAHS) [9], ROM, pain, impingement sign, and alpha angle in patients without and with subsequent THA after surgery using this technique.

\section{Materials and Methods}

From 2004 to 2007, we prospectively followed all 88 patients (105 hips) treated arthroscopically for a symptomatic cam or mixed impingement of the hip. All patients were evaluated clinically and radiographically by two independent observers $(\mathrm{MH}, \mathrm{AB})$ not directly involved in the care of the patients. The presence of FAI was diagnosed by the clinical examination, plain radiographs, and gadoliniumenhanced MRI. Preoperatively, all patients had an anteroposterior (AP) radiograph of the pelvis and a modified Dunn view in $45^{\circ}$ flexion. The presence of osteoarthritic signs was graded according to the classification of Tönnis and Heinecke [37]. As many of these radiographs were not scaled, we could not measure numerical joint space diminution. We excluded patients with any surgery on the affected hip, any clear history of precedent trauma, and preexisting Tönnis Grade III osteoarthrosis. The study included 60 males ( 73 hips) and 28 females ( 32 hips) with an average age of 40.9 years (range, 17-66 years) at the time of surgery. Twelve patients (17 males, two females) were operated on for bilateral symptomatic hip impingement.
Preoperatively, one hip had Tönnis Grade 0 osteoarthritis (0.9\%), 76 hips $(72.4 \%)$ had Tönnis Grade I, and 28 hips (26.7\%) had Tönnis Grade II. Intraoperatively, chondral lesions were Grade 1 in 34 hips (32.4\%), Grade 2 in 55 hips (52.4\%), and Grade 3 in 16 hips (15.2\%). Patients were followed a minimum of 1.3 years (average, 2.3 years; range, 1.3-4.1 years). No patients were lost to followup. All subjects gave informed consent to participate in the study. The study was performed in accordance with the World Medical Association Declaration of Helsinki and followed the guidelines for clinical investigation required by the authors' institution.

We performed hip arthroscopy with the patient in the supine position on a fracture table and generally under lumbar anesthesia. The leg was immobilized at approximately $20^{\circ}$ hip flexion by fixation of the foot in a fixation device (VacoPed ${ }^{\circledR}$; Oped GmbH, Oberlaindern, Germany), which was installed on a traction table to allow traction later during the operation. The second leg was kept away from the operation field with a special leg holder allowing for free positioning in all directions. The perineum was carefully positioned against a large, padded bolster to protect the genitalia and pudendal nerve. The hip was prepared and draped and then palpable landmarks such as the anterior superior iliac spine, the great trochanter, sartorius, and tensor fasciae latae were marked on the skin with a sterile pen. For better hemostasis, we injected under fluoroscopy control a diluted adrenalin solution around the capsule from a distal anterolateral approach $2 \mathrm{~cm}$ ventral to the anterior border of the greater trochanter. This needle also was used to determine the optimal level for the first portal. To obtain an optimal view of the neck and acetabular rim, the tip of the needle should reach the head-neck junction in the AP view between the superior and medial third of the neck and the needle should be perpendicular to the long axis of the femur. We made the skin incision to include the entrance point of the needle. In obese patients, this portal was placed even more medially, approximately 3 to $4 \mathrm{~cm}$ ventral to the anterior border of the trochanter. We inserted a blunt trocar through the gap between the vastus lateralis and gluteus medius muscles down to the surface of the capsule. After blunt dissection of the capsule, a $70^{\circ}$ arthroscope was introduced in the created extraarticular space. Then an anterior portal was placed directly lateral to the sartorius tendon approximately $8 \mathrm{~cm}$ distal to the anterior superior iliac spine corresponding with the inferior border of the femoral head-neck junction. In most cases, a third proximal anterolateral portal subsequently was needed to reach all parts of the joint with the instruments. This portal was situated approximately $2 \mathrm{~cm}$ proximal and $3 \mathrm{~cm}$ medial to the tip of the great trochanter, but its exact position was first localized by a cannula (Fig. 1). 

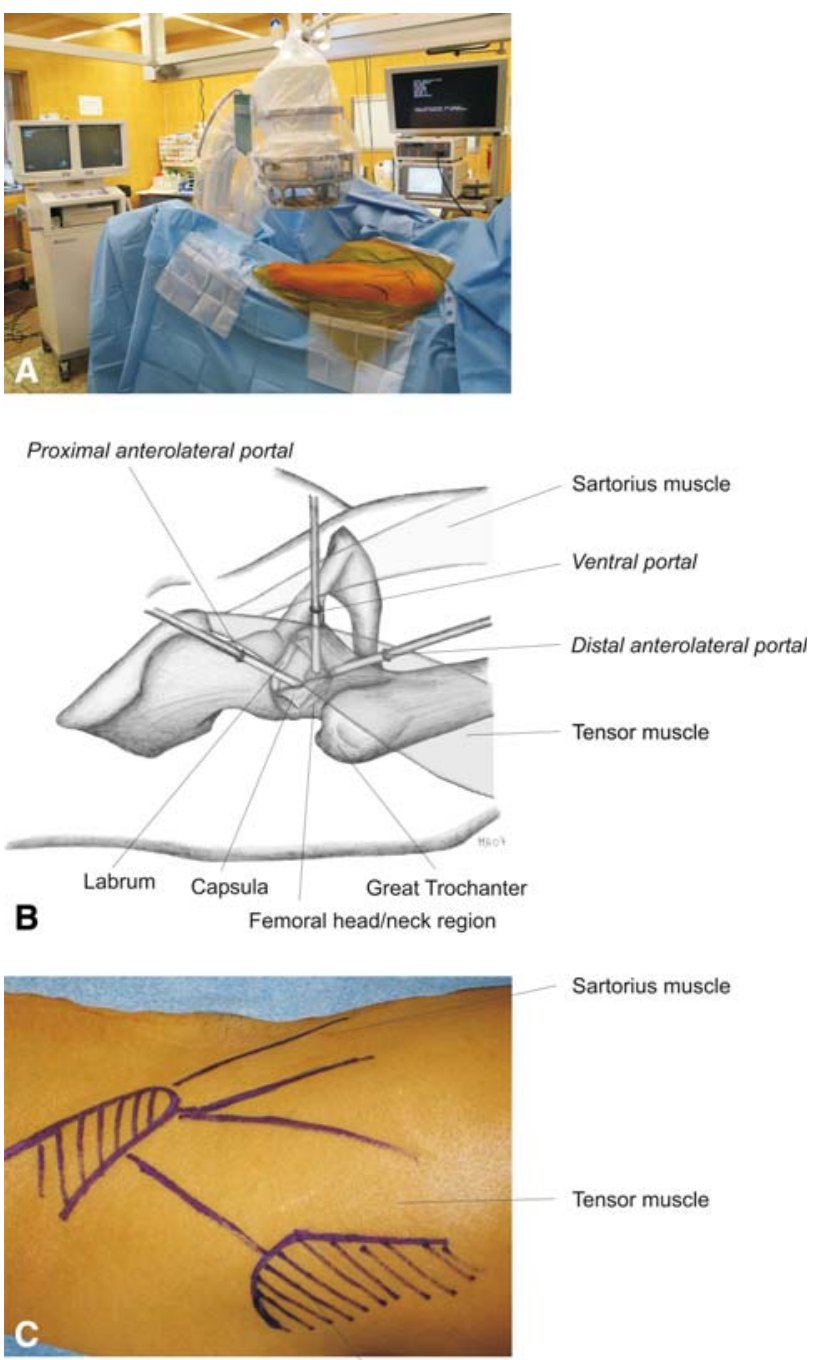

Great Trochanter

Fig. 1A-C (A) A photograph shows the overall setup for hip arthroscopy in the operating room. (B) A diagram shows positioning of the portals. (C) A photograph shows the intraoperative landmarks.

We inserted the instruments through the ventral portal. The joint capsule was prepared and observed using the Arthrocare ${ }^{\circledR}$ Vapor ${ }^{\mathbb{R}}$ (Arthrocare, Sunnyvale, CA) (Fig. 2). The Vapor ${ }^{\circledR}$ also was used to perform capsulotomy under direct observation, beginning ventrocranial in the lateral third of the capsule to avoid cartilage damage. The capsulotomy was continued parallel to the femoral neck to the labrum and, if necessary, $\mathrm{T}$-shaped along the acetabular rim for no more than approximately $1 \mathrm{~cm}$, thus avoiding the important capsular vessels. This allowed for preservation of the blood supply of the femoral head and prevented damage to the capsular reinforcing ligaments (iliofemoral ligament) and reflected head of the rectus femoris. In addition, it minimized the risk of iatrogenic labral lesions because the procedure was performed under direct visual control.
At this point, we applied traction using a standard traction table as described above and under direct arthroscopic control observed the labrum and the central compartment of the hip. Pathologic changes associated with impingement, including articular cartilage softening or delamination, osteophytes, and pathologic findings of the fovea, could be identified. One of us (RFH) graded the cartilage and labral damage intraoperatively (Table 1). In accordance with the intraarticular findings, operative procedures included resection of severely damaged parts of the labrum (partial limbectomy), removal of os acetabuli and loose intraarticular bodies, débridement of delaminated cartilage (in cases of flaps, frayed edges, fibrillation), microfracturing (in cases of Outerbridge Grade IV lesions), and shortening of the acetabular rim (in cases of mixed impingement). We then removed the traction and examined the peripheral compartment of the hip. For better observation of the headneck junction, the superior capsule was held away by a Wissinger rod. We used this instrument like a Hohmann retractor over the proximal anterolateral portal.

We used a straight 5.5-mm Acromionizer ${ }^{\circledR}$ (Smith and Nephew Endoscopy, Andover, MA) to restore the normal femoral head-neck offset. To facilitate correct offset restoration, a T-shaped marking initially was made on the pathologic bone/cartilage mass to determine the extent of resection. Our aim was to achieve impingement-free ROM of $110^{\circ}$ flexion and an internal rotation and adduction greater than $20^{\circ}$, given the limitation that the resection had to be less than $20 \%$ of the femoral neck diameter to minimize the risk of an iatrogenic-induced femoral neck fracture [23]. This threshold was chosen because Mardones et al. [24] suggested, based on a cadaver study, resection of 30\% of the femoral neck diameter substantially decreased the amount of energy required to produce a fracture.

We then took the leg out of the fixation device to document the impingement had been eliminated in maximal flexion and internal rotation; if necessary, we extended the bony resection to achieve impingement-free motion. In addition to resecting bone causing impingement, we performed the following additional procedures: partial labral resection in 85 hips $(81.0 \%)$, removal of os acetabuli in 12 hips $(11.4 \%)$, and deep cartilage lesion débridment and microfracture in 33 hips (31.4\%). Forty-eight hips (45.7\%) were considered to have mixed impingement and therefore trimming of the acetabular rim was performed. The average operation time was 130.7 minutes (range, $70-150$ minutes), whereas traction time averaged 28.6 minutes (range, 7 60 minutes).

We recorded perioperative complications by asking specifically about hypesthesia and signs of wound-healing problems and performed a clinical examination. Postoperatively, all patients routinely were prescribed oral indomethacin $(3 \times 25 \mathrm{mg} /$ day $)$ for prophylaxis against 

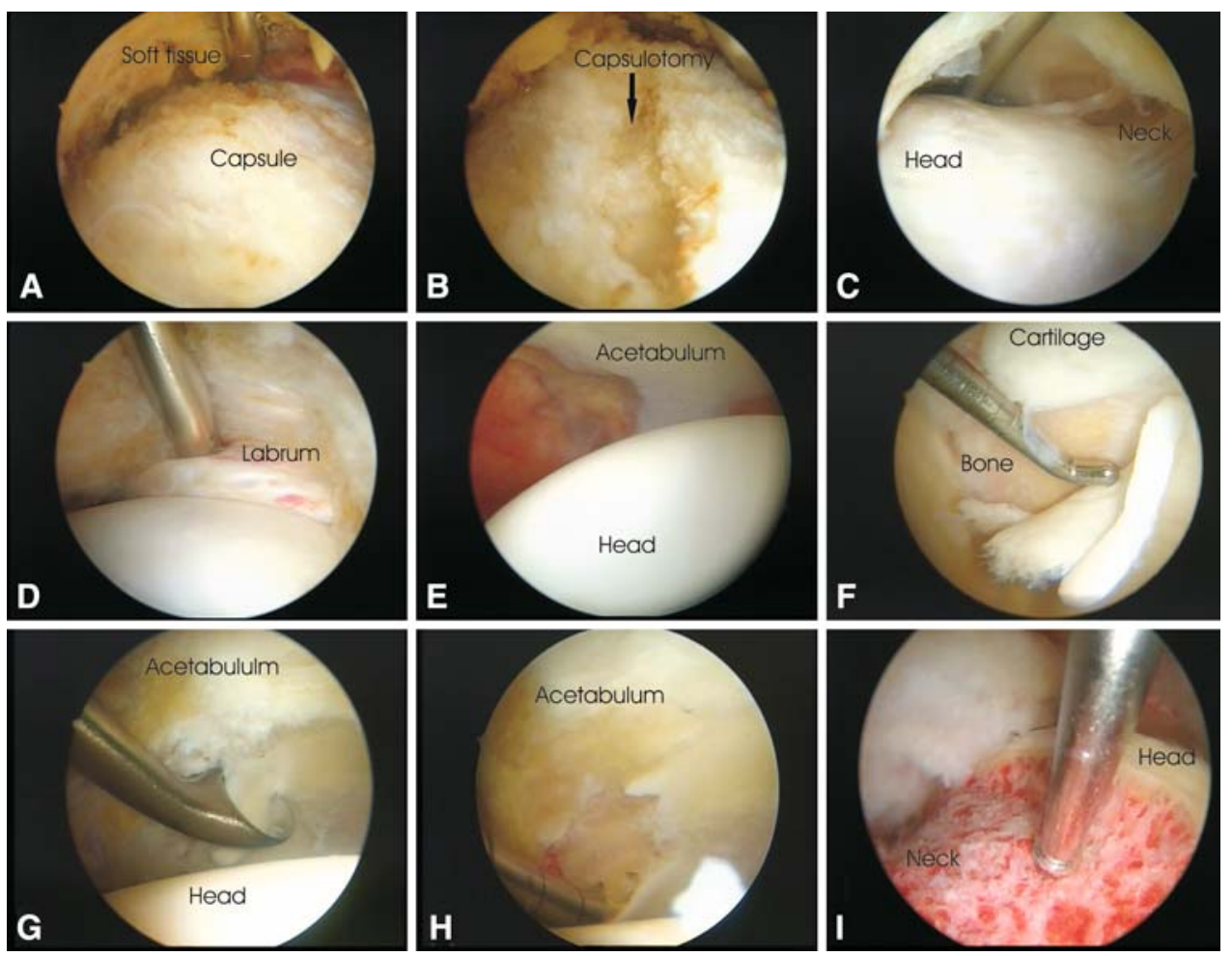

Fig. 2A-I A hip arthroscopy in a patient with FAI is illustrated. (A) The anterolateral joint capsule is prepared with the Arthrocare ${ }^{\circledR}$ Vapor ${ }^{\mathbb{R}}$. (B) Capsulotomy under direct observation is performed, beginning in the lateral third to avoid cartilage damage. The capsulotomy is continued parallel to the femoral neck to the labrum and, if necessary, T-shaped along the acetabular rim. Inspection of the peripheral compartment shows the pathologic bump at (C) the femoral head/neck and (D) the intact labrum. For better observation of the head-

Table 1. Classification used for arthroscopically found cartilage lesions

\begin{tabular}{ll}
\hline Grade & Description \\
\hline $1 \quad \begin{array}{c}\text { Chondromalacia not more than Grade II (Outerbridge } \\
\text { classification [27]) and limited to the impingement zone } \\
\text { Chondromalacia more than Grade II (Outerbridge } \\
\text { classification) in the impingement zone and Grades I-II in } \\
\text { the rest of the hip } \\
\text { Chondromalacia more than Grade II (Outerbridge } \\
\text { classification) in the impingement zone and diffuse } \\
\text { chondromalacia more than Grade II in the rest of the hip }\end{array}$ \\
a
\end{tabular}

heterotopic ossification for 3 weeks and a subcutaneously applied low-molecular-weight heparin at a weight-dependent prophylactic dosage for at least 2 weeks or as long as they were not fully weightbearing. Patients generally were allowed full weightbearing. In case of microfracturing, we recommended partial weightbearing of 15 to $20 \mathrm{~kg}$ for 6 weeks. All patients underwent supervised physical therapy twice a week for 6 to 8 weeks. Low-impact sports were allowed after 6 weeks, with a minimum of 3 months for stop-and-go and high-impact sports. neck junction, the superior capsule is held away by a Wissinger rod. Inspection of the central compartment under traction shows $(\mathbf{E})$ intact cartilage and (F) delaminated cartilage at the impingement zone of the acetabulum. (G) Débridement of completely delaminated cartilage and (H) microfracturing of débrided areas are performed. (I) The normal femoral head-neck offset is restored with a straight $5.5-\mathrm{mm}$ Acromionizer ${ }^{\circledR}$.

We routinely saw patients at 6 weeks, 3 months, and then as needed and at particular invitation for study followup in October 2007. The NAHS [9] was completed by all patients before surgery and at the last followup. The NAHS was chosen because it is a validated, self-administered score, excludes physician bias, and is designed particularly for younger patients with specific hip problems without relevant arthritic degeneration. Preoperatively and at latest followup, two of us $(\mathrm{MH}, \mathrm{AB})$ evaluated all patients for pain (visual analog scale [VAS], 0-10), pain localization, ROM with the patient in the supine position, and signs of impingement. Patients were examined for signs of anterior impingement by stressing the hip in full flexion and internal rotation [22].

Preoperatively gadolinium-enhanced MRI was performed routinely in all patients for diagnostic purposes; for study purposes postoperative MRI was performed in all patients. We examined the postoperative MRI for any sign of osteonecrosis or occult fracture. Preoperatively and postoperatively, two of us (MH, AB) measured the angle alpha, as described by Nötzli et al. [26], on MRI at a level parallel to the femoral neck passing through the center of the head 
Fig. 3A-H The images illustrate the case of a 45-year-old man with symptomatic bilateral femoroacetabular cam impingement. (A) A preoperative AP radiograph of the pelvis and (C) modified Dunn view in $45^{\circ}$ flexion show the pathologic bumps at the femoral head/neck junctions (arrows). (B) A postoperative AP radiograph of pelvis and (D) modified Dunn view in $45^{\circ}$ flexion show absence of pathologic bumps. (E) A preoperative arthro-MRI shows an alpha angle of $68^{\circ}(\mathbf{F})$ whereas a postoperative MRI shows an alpha angle of $48^{\circ}$. Intraoperative photographs show $(\mathbf{G})$ the pathologic bump at the femoral head/ neck junction and $(\mathbf{H})$ the femoral head/neck junction after correction of offset.
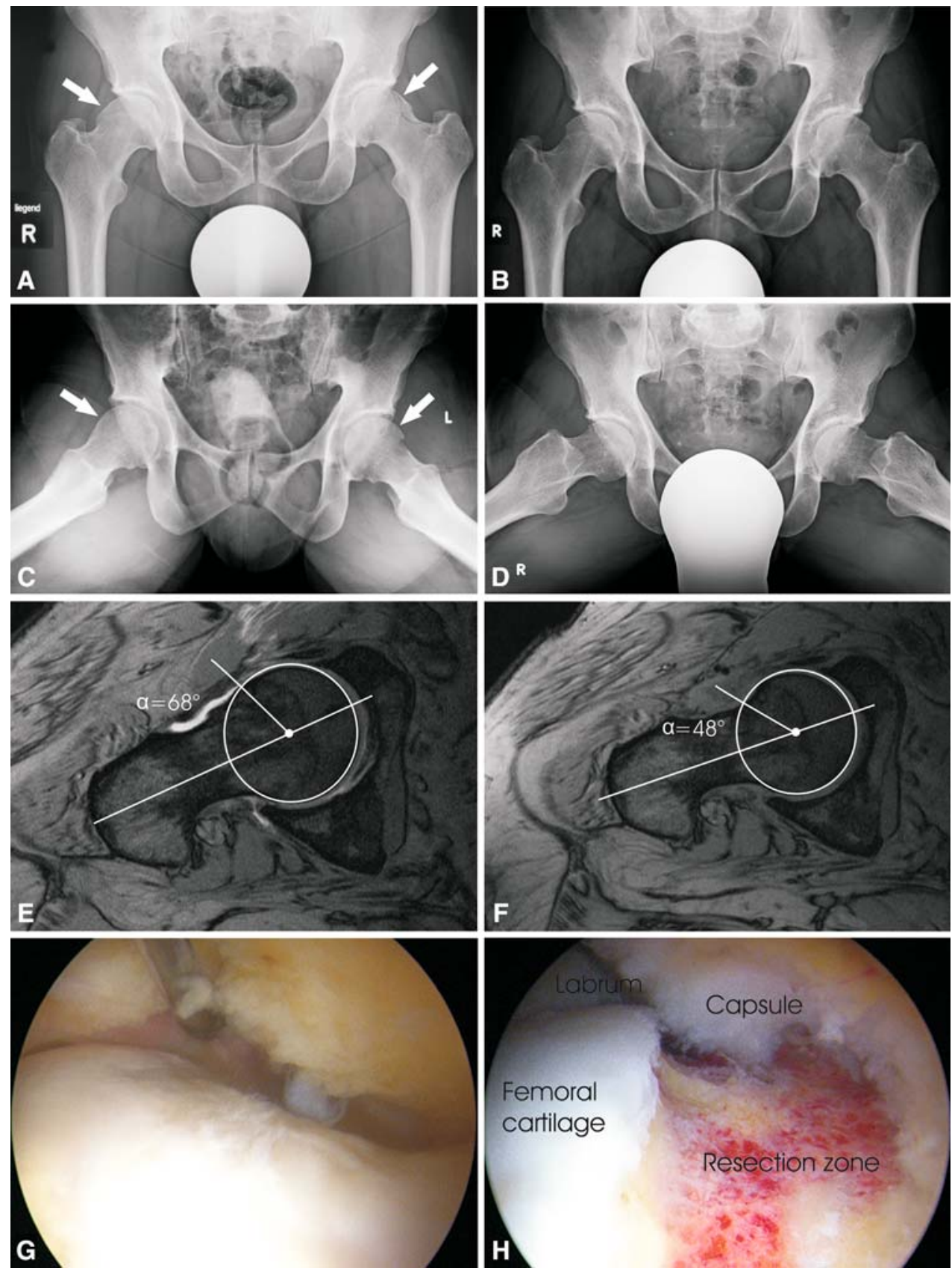

(Fig. 3). In accordance with others [2, 26], an angle less than $50^{\circ}$ was considered normal (Fig. 4).

We determined differences in preoperative and postoperative metric variables using the paired t test (comparison of preoperative and postoperative alpha angle, NAHS, VAS for pain, ROM) and in metric variables of different groups (ie, patients with and without THA) using the unpaired $\mathrm{t}$ test. Before this, a test for normal statistical distribution of values and the Levene test were performed in all analyses to prove variances in the two groups were equal. SPSS ${ }^{\circledR}$ software (Version 15.0; SPSS Inc, Chicago, IL) was used for all analyses.

\section{Results}

No operation was cancelled for intraoperative adverse events. In all cases, we could sufficiently observe the joint. In no patient did we identify iatrogenic labral damage resulting from arthroscopically entering the joint. Complications occurred in $12(11 \%)$ hips. All were minor, including dysesthesia/hypesthesia of pudendal and lateral cutaneous femoral nerves in nine, and sciatic nerve neurapraxia with hypesthesia of the instep region in two. One very obese female patient sustained a superficial tear of her labia minora resulting from the traction device. All 


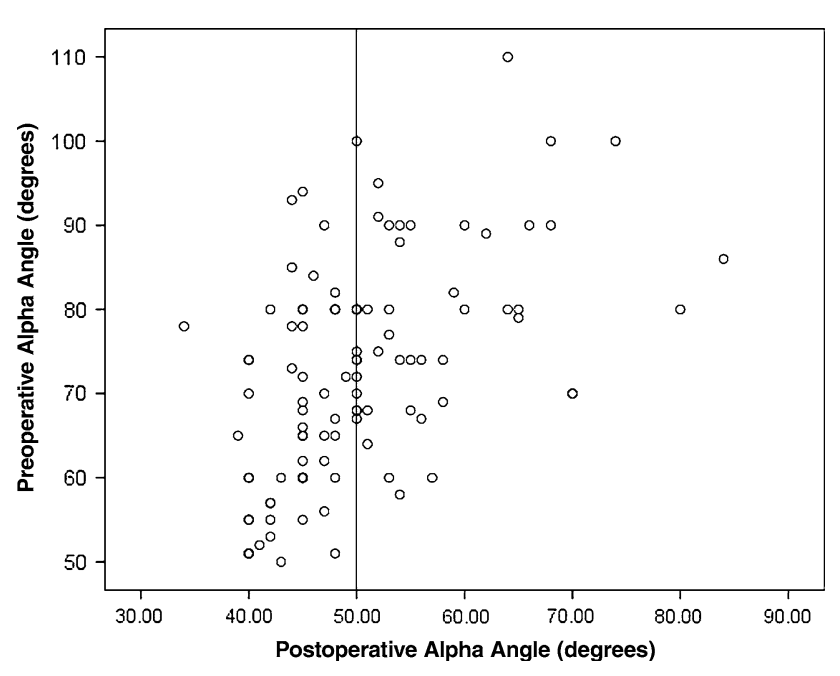

Fig. 4 A box plot shows preoperative and postoperative alpha angles. An angle less than $50^{\circ}$ was considered normal. Our aim was to achieve an impingement-free ROM of $110^{\circ}$ flexion and an internal rotation and adduction greater than $20^{\circ}$, given the limitation that the resection had to be less than $20 \%$ of the femoral neck diameter to minimize the risk of an iatrogenic-induced femoral neck fracture.

Table 2. Results summary

\begin{tabular}{|c|c|c|c|c|c|}
\hline \multirow[t]{2}{*}{ Variable } & \multicolumn{2}{|c|}{ Peroperative } & \multicolumn{2}{|c|}{ Postoperative* } & \multirow[t]{2}{*}{$\mathrm{p}$ Value } \\
\hline & Average & Range & Average & Range & \\
\hline $\begin{array}{l}\text { NAHS } \\
\text { (points) }\end{array}$ & 56.8 & $15-92.5$ & 84.6 .0 & $47.5-100$ & $<0.001$ \\
\hline $\begin{array}{l}\text { ROM: internal } \\
\text { rotation }\end{array}$ & $4.9^{\circ}$ & $-30^{\circ}-30^{\circ}$ & $22.9^{\circ}$ & $-5^{\circ}-50^{\circ}$ & $<0.001$ \\
\hline Flexion & $110.0^{\circ}$ & $60^{\circ}-150^{\circ}$ & $123.3^{\circ}$ & $70^{\circ}-150^{\circ}$ & $<0.001$ \\
\hline $\begin{array}{l}\text { Pain } \\
\text { (VAS 1-10) }\end{array}$ & 5.5 & $0-9$ & 1.5 & $0-6$ & $<0.001$ \\
\hline Alpha angle & $72.8^{\circ}$ & $51^{\circ}-110^{\circ}$ & $50.3^{\circ}$ & $34^{\circ}-84^{\circ}$ & $<0.001$ \\
\hline
\end{tabular}

* Data are based on patients not undergoing THA during followup; NAHS = Nonarthritic Hip Score; ROM = range of motion; VAS = visual analog scale.

complications resolved completely without additional treatment within months. There were no femoral neck fractures related to surgery and the postoperative MRI did not reveal any evidence of osteonecrosis of the femoral head.

The 96 hips (91\%) not requiring THA had improved NAHS, range of flexion and internal rotation, pain, and alpha angle (Table 2). In the preoperative examination, 99 hips $(94 \%)$ had a positive anterior impingement sign. At the latest followup, this had decreased to 17 hips (18\%).

When comparing patients with a pure cam impingement $(\mathrm{n}=57,54.3 \%)$ with those having mixed impingement treated with rim trimming $(\mathrm{n}=48,45.7 \%)$, no differences were found with respect to preoperative Tönnis grade, chondral damage, NAHS, ROM, or VAS for pain.
In nine hips (9\%), THA subsequently was performed, including five surface replacements and four conventional hip prostheses. The average age of these patients (46.1 years) was similar to $(\mathrm{p}=0.1)$ the average age (40.5 years) of the rest of the cohort at the time of index surgery. Five of these patients preoperatively had osteoarthritis Tönnis Grade II, and four had Grade I. Intraoperatively, we observed Grade 3 osteochondral lesions in four hips and Grade 2 in five hips. The average preoperative and postoperative alpha angles were similar (both $p=0.7$ ) to those of the rest of the patients. The preoperative NAHS was lower $(p=0.04)$ than that in the rest of the cohort. No other reoperations were performed in the rest of the cohort.

\section{Discussion}

Open surgical hip dislocation and femoroacetabular correction for FAI is a well-accepted method of treatment for FAI associated with none or only mild chondral damage and yields good to excellent results in short- and midterm followups $[1,4,25]$. However, this operation is associated with a large surgical exposure, several weeks of partial weightbearing, and a considerable number of short- and long-term complications, such as pain over the trochanteric region, which makes screw removal necessary [1, 24]. Arthroscopic therapy for FAI has become a promising alternative. However, the procedure is associated with several technical difficulties, such as safe entering of the joint capsule, and few outcome studies are available $[15,29,33]$. We therefore describe a technique that provides a way to securely penetrate the joint capsule, which enables sufficient observation of the pathologic head-neck region and arthroscopic correction for FAI. We then report the complication rate; the number of patients who had subsequent THA; and the NAHS [9], ROM, pain, impingement sign, and alpha angle in patients with and without subsequent THA after surgery using this technique.

The two major limitations of our study are the lack of a control group and the short followup. A longer followup is necessary to determine whether, and especially in which patients, correction for FAI may avert the pathologic sequence of events starting with impingement and resulting in end-stage arthrosis at a young age. Labrum resection instead of labrum refixation might be another limitation of this study. Recently published studies seem to favor labrum refixation instead of resection $[5,10,11,30]$. But, as all of these studies have short followups, no definitive judgment on this issue can be made at this time.

Another potential flaw of the study might be the use of a not well-established grading system for cartilage lesions. However, we decided to use this grading scale because, at 
the time of the first patients, no validated and widely used cartilage grading system was available that took into account the specific lesions associated with FAI. We therefore thought it would be helpful to use a grading system that derives from the classic Outerbridge classification [27] but includes the special issues of FAI cartilage lesions in terms of limited extent of typical impingement lesions and later including the whole joint.

Arthroscopic correction for FAI seems to be a feasible surgical treatment. No arthroscopy was canceled because of surgical difficulties. Sufficient observation of the diseased area with our technique of extraarticular preparation of the capsule and entering the joint under direct visual control were achieved in all cases. We did not identify any patient with osteonecrosis of the femoral head nor any femoral neck fractures related to the surgery. The number of neurologic complications in our series seems high at first sight compared with numbers reported in other studies [7, 14, 30]. However, this might be because we were searching explicitly for dysesthesia/paresthesia instead of noting what patients reported [30]. Nerve lesions have been reported to be a particular risk of hip arthroscopy because the anterolateral portal is in proximity to the superior gluteal neurovascular bundle, whereas the anterior portal is in proximity to the lateral femoral cutaneous nerve and the femoral neurovascular bundle [8]. The primary risk of traction is injury to the sciatic nerve [14]. We believe this is best minimized by directly controlled traction not exceeding the extent needed to enter the central compartment, by keeping the hip in slight flexion, and by keeping traction time as short as possible. Pudendal traction neurapraxia risk can be reduced with the use of a padded perineal bolster $[16,31]$.

Our arthroscopic approach as described previously might be a step in this direction, allowing use of traction only after establishing the arthroscopic portals and under direct visual control, thus keeping traction time and force at a strict minimum. The average traction time of 28.6 minutes in our series is far less that reported [17] owing to the fact that it was used only after having placed the portals and after capsulotomy. Another factor for shorter traction time compared with reported time might be the fact that no labral refixation was performed in our study cohort. The method of entering the capsule under direct visual control avoids iatrogenic labrum and cartilage damage.

Clinical and radiographic results from other studies can be compared with our outcome only with precautions. Most of the studies use outcome scores designed for patients with osteoarthritis, such as the WOMAC and Harris hip score [7, 14] (Table 3). This may lead to a larger number of higher scores because these scores consider a wider range of intensity of symptoms and are less sensitive to the differences in minimally symptomatic patients at or

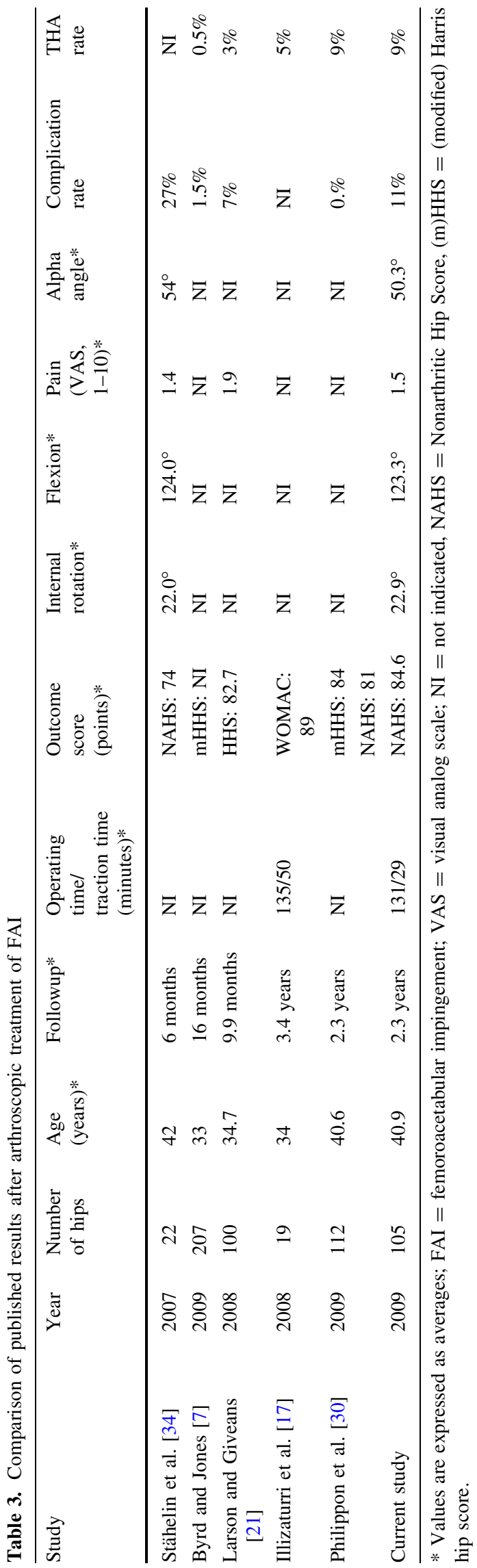


before the beginning of osteoarthritis. We believe the NAHS [9] is a more appropriate, reliable, and validated outcome measure for this group of patients. In general, the postoperative average of 84.6 points is comparable to what is reached in other studies [7,21]. Data for postoperative ROM are sparse. However, our results are in accordance with those of Stähelin et al. [34]. Our data suggest pain relief similar to that reported in two studies [21, 34]. In our study, the average postoperative alpha angle, as measured on MRI, was $50.3^{\circ}$, which suggests good correction of the underlying disorder. However, comparison to other studies is difficult, as these measurements rarely are provided.

Nine percent of our patients underwent THA during followup. This percentage seems in accordance with other studies with similar followups and patient ages. In a recent study of 112 patients with an average age of 40.6 years and a mean followup of 2.3 years, 10 patients (9\%) underwent THAs during followup [30]. Proper indication for FAI correction is mandatory to achieve good results in terms of pain relief, increase of ROM, and prevention of osteoarthritis. Additional studies are needed to better characterize the group of patients most benefiting from this procedure and to determine long-term outcome of arthroscopically treated FAI. It cannot fully be excluded that a part of the pain reduction in short- and midterm followups is related to labral débridement rather than removal of the impinging bony formation.

We presented a new technique of extracapsular preparation and capsular penetrance under direct visual control for treatment of FAI. We found postoperative improvement in all outcome measures at an average followup of 2.3 years. The long-term development after correction for FAI is required to see if the symptomatic relief persists.

\section{References}

1. Beaulé PE, Le Duff MJ, Zaragoza E. Quality of life following femoral head-neck osteochondroplasty for femoroacetabular impingement. J Bone Joint Surg Am. 2007;89:773-779.

2. Beaulé PE, Zaragoza E, Motamedi K, Copelan N, Dorey FJ. Three-dimensional computed tomography of the hip in the assessment of femoroacetabular impingement. J Orthop Res. 2005;23: 1286-1292.

3. Beck M, Kalhor M, Leunig M, Ganz R. Hip morphology influences the pattern of damage to the acetabular cartilage: femoroacetabular impingement as a cause of early osteoarthritis of the hip. J Bone Joint Surg Br. 2005;87:1012-1018.

4. Beck M, Leunig M, Parvizi J, Boutier V, Wyss D, Ganz R. Anterior femoroacetabular impingement: part II. Midterm results of surgical treatment. Clin Orthop Relat Res. 2004;418:67-73.

5. Bedi A, Chen N, Robertson W, Kelly BT. The management of labral tears and femoroacetabular impingement of the hip in the young, active patient. Arthroscopy. 2008;24:1135-1145.

6. Byrd JW, Jones KS. Prospective analysis of hip arthroscopy with 2-year follow-up. Arthroscopy. 2000;16:578-587.
7. Byrd JW, Jones KS. Arthroscopic femoroplasty in the management of cam-type femoroacetabular impingement. Clin Orthop Relat Res. 2009;467:739-746.

8. Byrd JW, Pappas JN, Pedley MJ. Hip arthroscopy: an anatomic study of portal placement and relationship to the extraarticular structures. Arthroscopy. 1995;11:418-423.

9. Christensen CP, Althausen PL, Mittleman MA, Lee JA, McCarthy JC. The nonarthritic hip score: reliable and validated. Clin Orthop Relat Res. 2003;406:75-83.

10. Espinosa N, Beck M, Rothenfluh DA, Ganz R, Leunig M. Treatment of femoro-acetabular impingement: preliminary results of labral refixation. Surgical technique. J Bone Joint Surg Am. 2007;89(suppl 2, pt 1):36-53

11. Espinosa N, Rothenfluh DA, Beck M, Ganz R, Leunig M. Treatment of femoro-acetabular impingement: preliminary results of labral refixation. J Bone Joint Surg Am. 2006;88:925-935.

12. Ganz R, Gill TJ, Gautier E, Ganz K, Krügel N, Berlemann U. Surgical dislocation of the adult hip: a technique with full access to the femoral head and acetabulum without the risk of avascular necrosis. J Bone Joint Surg Br. 2001;83:1119-1124.

13. Ganz R, Parvizi J, Beck M, Leunig M, Nötzli H, Siebenrock KA. Femoroacetabular impingement: a cause for osteoarthritis of the hip. Clin Orthop Relat Res. 2003;417:112-120.

14. Griffin DR, Villa RN. Complications of arthroscopy of the hip. J Bone Joint Surg Br. 1999;81:604-606.

15. Guanche CA, Bare AA. Arthroscopic treatment of femoroacetabular impingement. Arthroscopy. 2006;22:95-106.

16. Ilizaliturri VM Jr. Complications of arthroscopic femoroacetabular impingement treatment: a review. Clin Orthop Relat Res. 2009;467:760-768.

17. Ilizaliturri VM Jr, Orozco-Rodriguez L, Acosta-Rodríguez E, Camacho-Galindo J. Arthroscopic treatment of cam-type femoroacetabular impingement: preliminary report at 2 years minimum follow-up. J Arthroplasty. 2008:23;226-234.

18. Ito K, Minka MA 2nd, Leunig M, Werlen S, Ganz R. Femoroacetabular impingement and the cam-effect: a MRI-based quantitative anatomical study of the femoral head-neck offset. $J$ Bone Joint Surg Br. 2001;83:171-176.

19. Khanduja V, Villar R. The arthroscopic management of femoroacetabular impingement. Knee Surg Sports Traumatol Arthrosc. 2007; $15: 1035-1040$.

20. Krueger A, Leunig M, Siebenrock KA, Beck M. Hip arthroscopy after previous surgical hip dislocation for femoroacetabular impingement. Arthroscopy. 2007;23:1285-1289.

21. Larson CM, Giveans MR. Arthroscopic management of femoroacetabular impingement: early outcomes measures. Arthroscopy. 2008;24:540-546.

22. MacDonald SJ, Garbuz D, Ganz R. Clinical evaluation of the symptomatic young adult hip. Semin Arthroplasty. 1997;8:3-9.

23. Mardones RM, Gonzalez C, Chen Q, Zobitz M, Kaufman KR, Trousdale RT. Surgical treatment of femoroacetabular impingement: evaluation of the effect of the size of the resection. J Bone Joint Surg Am. 2005;87:273-279.

24. Mardones RM, Gonzalez C, Chen Q, Zobitz M, Kaufman KR, Trousdale RT. Surgical treatment of femoroacetabular impingement: evaluation of the effect of the size of the resection. Surgical technique. J Bone Joint Surg Am. 2006;88(suppl 1):84-91.

25. Murphy S, Tannast M, Kim YJ, Buly R, Millis MB. Debridement of the adult hip for femoroacetabular impingement: indications and preliminary clinical results. Clin Orthop Relat Res. 2004;429: $178-181$.

26. Nötzli HP, Wyss TF, Stoecklin CH, Schmid MR, Treiber K, Hodler J. The contour of the femoral head-neck junction as a predictor for the risk of anterior impingement. J Bone Joint Surg Br. 2002;84:556-560. 
27. Outerbridge RE. The etiology of chondromalacia patellae. J Bone Joint Surg Br. 1961;43:752-757.

28. Peters CL, Erickson JA. Treatment of femoro-acetabular impingement with surgical dislocation and débridement in young adults. J Bone Joint Surg Am. 2006;88:1735-1741.

29. Philippon M, Schenker M, Briggs K, Kuppersmith D. Femoroacetabular impingement in 45 professional athletes: associated pathologies and return to sport following arthroscopic decompression. Knee Surg Sports Traumatol Arthrosc. 2007;15:908-914.

30. Philippon MJ, Briggs KK, Yen YM, Kuppersmith DA. Outcomes following hip arthroscopy for femoroacetabular impingement with associated chondrolabral dysfunction: minimum two-year follow-up. J Bone Joint Surg Br. 2009;91:16-23.

31. Philippon MJ, Funke EL, Munzinger U. Complications in hip arthroscopy. Arthroscopy. 1996;12:156-159.

32. Philippon MJ, Maxwell RB, Johnston TL, Schenker M, Briggs KK. Clinical presentation of femoroacetabular impingement. Knee Surg Sports Traumatol Arthrosc. 2007;15:1041-1047.
33. Sampson TG. Arthroscopic treatment of femoroacetabular impingement: a proposed technique with clinical experience. Instr Course Lect. 2006;55:337-346.

34. Stähelin L, Stähelin T, Jolles BM, Herzog RF. Arthroscopic offset restoration in femoroacetabular cam impingement: accuracy and early clinical outcome. Arthroscopy. 2008;24:51-57.

35. Sussmann PS, Ranawat AS, Lipman J, Lorich DG, Padgett DE, Kelly BT. Arthroscopic versus open osteoplasty of the head-neck junction: a cadaveric investigation. Arthroscopy. 2007;23:12571264.

36. Tannast M, Goricki D, Beck M, Murphy SB, Siebenrock KA. Hip damage occurs at the zone of femoroacetabular impingement. Clin Orthop Relat Res. 2008;466:273-280.

37. Tönnis D, Heinecke A. Acetabular and femoral anteversion: relationships with osteoarthritis of the hip. J Bone Joint Surg Am. 1999;81:1747-1770.

38. Wettstein M, Dienst M. [Arthroscopic treatment of femoroacetabular impingement] [in German]. Orthopäde. 2006;35:85-93. 